\title{
Toplumsal Cinsiyet Eşitsizliğinin Hemşirelik Mesleğine Yansımaları
}

\author{
Reflections of Gender Inequality on Nursing Profession
}

Fatma BAŞARAN ${ }^{1}$, Nedime KÖŞGEROĞLU ${ }^{2}$

\section{ÖZ}

$\mathrm{Bu}$ derleme çalışmasında, toplumsal cinsiyet eşitsizliğinin hemşirelik mesleğine yansımalarının ele alınması amaçlanmıştır. Toplumun bireylere yıllardır kadın ya da erkek olarak yüklemiş olduğu roller, sorumluluklar, tutumlar ve davranışlar toplumsal cinsiyet eşitsizliğinin temelini oluşturmaktadır. Günlük yaşantımızı, aile içi rollerimizi, eğitim ve çalışma hayatımız başta olmak üzere tüm yaşantımızı etkisi altına alan toplumsal cinsiyet kavramı aslında sosyal, kültürel ve öğrenilen bir kavramdır. Ulusal ve uluslararası önemli birçok sözleşme ve faaliyetlerde yer verilen toplumsal cinsiyet eşitsizliğinin en çok etkilediği alanlardan biri de, kadın mesleği olarak bilinen hemşirelik mesleğidir. Kadına toplum tarafından yüklenen rollerden (bakım verme, şefkat gibi) dolayı "kadın mesleği”" olarak bilinen hemşirelik mesleğinde erkek hemşireler uzun yıllardır yer almasına rağmen cinsiyet eşitsizliğinden dolayı istenen sonuç elde edilememiştir. Literatürde yapılan çalışmalar göz önünde bulundurulduğunda; erkek hemşirelere hala nasıl hitap edilmesi konusunda bir netliğin olmadığı, erkeklere farklı bir unvanın verilmesinin toplumsal cinsiyet ayrımcılığına neden olup olmayacağı, erkeklerin mesleğe katılmalarıyla meslek adına istenen değişimin elde edilip edilmediği, erkek hemşirelerin kadın hastaya bakım verip vermemesinin ne denli doğru olduğu ya da hastada utanma ve sıkılmaya neden olduğu, erkeklerin hem eğitim hem de çalışma alanında soyutlandığına dair farklı sonuçlar mevcuttur.

Anahtar Kelimeler: Erkek Hemşire, Eşitsizlik, Hemşirelik Mesleği, Toplumsal Cinsiyet.

\begin{abstract}
In this review study, it is aimed to discuss the reflections of gender inequality on the nursing profession. The roles, responsibilities, attitudes and behaviors that society has placed on individuals as men or women for years are the basis of gender inequality. The concept of gender, which affects our daily life, our family roles, our entire life, especially in our education and working life, is actually a social, cultural and learned concept. One of the areas where gender inequality affects most national and international important contracts and activities is the nursing profession known as women's profession. Despite the fact that male nurses have been in the nursing profession, which is known as "women's profession" due to the roles imposed on women by society (such as care and compassion), the desired result could not be achieved due to gender inequality. Considering the studies in the literature; there is still no clarity in how to address male nurses, whether giving the men a different title will cause gender discrimination, whether the desired change in the name of the profession is achieved by the participation of men in the profession, how accurate it is whether male nurses give care to the female patient or not There are different results that cause boredom and that men are abstracted in both education and work.
\end{abstract}

Keywords: Male Nurse, Inequality, Nursing Profession, Gender.

\footnotetext{
${ }^{1}$ Arș. Gör. Ağrı İbrahim Çeçen Üniversitesi Sağlık Yüksekokulu Hemșirelik Bölümü, f.zeren89@gmail.com, ORCID: 0000-0002-6866-8678

${ }^{2}$ Prof. Dr. Rumeli Üniversitesi, Sağlık Hizmetleri Meslek Yüksekokulu, Tıbbi Hizmetler ve Teknikler Bölümü, nkosgeroglu@gamil.com, ORCID: 0000-0003-2567-9868 


\section{GíRiş}

Erkek ve kadın tarafindan yerine getirilmesi beklenen roller ile erkek veya kadın olmaya atfedilen anlamlar, genellikle bireylerin erkek veya kadın olmalarının normal sonucu olarak görülmektedir. Aslında erkekler ile kadınlar arasındaki tek ayırım biyolojiktir ve bu farklılığa sebep olan ise "y kromozomu"dur. Fakat toplumsallaşma süreci, toplumun beklentileri, erkek ya da kadın tarafından gerçekleştirilmesi beklenen roller, basmakalıp düşünceler bu farklılaşmaya farklı bir boyut kazandırıp, erkek ya da kadının davranışlarının temelini oluşturmaktadır. $\mathrm{Bu}$ farklılaşma, kadınlar açısından her alanda birçok eşitsizliğin doğmasında önemli rol oynamaktadır. ${ }^{1,2}$

Biyolojik ve toplumsal olarak pek çok noktada önemli işlevi olan cinsiyet kavramı, erkek veya kadın olmanın biyolojik yönünü tanımlayan, üreme işlevleriyle bağlantılı demografik bir özelliktir. Cinsiyet kavramı genel olarak, bedenin dişi ya da erkek olarak tanımlanmasına yol açan anatomik, fizyolojik ve genetik farklılıkların açıklanmasında kullanılır. ${ }^{3}$ Cinsiyet, farklı yönlerden incelenen ve farklı disiplinler tarafindan ele alınan bir özelliktir. Biyoloji, psikoloji, antropoloji ve sosyoloji gibi farklı alanlarda ele alınmaktadır. Cinsiyet kavramı fizyolojik ve anatomik özelliklerinin dışında, toplumsal anlamıyla karşımıza çıkmaktadır. Toplumsal boyutu ile ele alınan ve her alanda kendini gösteren cinsiyet kavramı toplumsal cinsiyet (gender) olarak adlandırılmaktadır. ${ }^{2,4}$ Toplumsal cinsiyet terimi ilk kez 1972'de Ann Oakley tarafından kullanılmıştır. Oakley toplumsal cinsiyet kavramının büyük ölçüde biyolojiden ayrıldığı ve farklılaştığ1 kısımlarını ortaya koyarken, bu kavramın toplumun bütün süreçlerini belirleyen temel öğe olduğuna da dikkat çekmiştir. ${ }^{5}$

Toplumsal cinsiyet (gender), erkeğin ve kadının sosyal olarak belirlenmiş ve yapılandırılmış kişilik özelliklerini, sorumluluklarını, rollerini, tutumlarını ve davranışlarını ele almaktadır. Kısacası; bireyin kendisini erkek ya da kadın olarak nasıl algıladığıdır. Cinsiyet biyolojik farkl11kklara toplumsal cinsiyet ise toplumsal farklılıklara işaret eder. Toplumsal cinsiyet kavramının temelinde, erkek ve kadın olarak toplumun bizi nasıl algıladığı, nasıl gördüğü ve nasıl davranmamızı beklediği ile ilgili beklentiler, roller, değerler ve yargilar bulunmaktadır. İnsanlar erkek ya da dişi cinsiyeti ile dünyaya gelir ve toplumun bireyin cinsiyetine yüklediği roller çerçevesinde erkek ya da kız çocuk olmayı öğrenerek büyürler. Toplumsal cinsiyet sosyal, kültürel ve öğrenilen bir kavramdır. $\mathrm{Bu}$ yüzden toplumsal cinsiyet kavram1, zaman içerisinde değişiklik göstermekte, bireyleri ve toplumları yaşamın her döneminde farklı șekillerde ve farklı boyutlarda etkilemektedir. ${ }^{6,7} \mathrm{Bu}$ kavram ayn zamanda yaygin olarak cinsiyetler arasındaki uyuşmazlıkları ve eşitsizlikleri ne kadar meşrulaştırdığının bir göstergesidir. Kısacası; toplumsal cinsiyet birlikte doğduğumuz veya sahip olduğumuz bir kavram değil, zamanla ortaya çıkardığımız/meydana getirdiğimiz bir kavramdir. $^{8}$

Toplumsal cinsiyet kavramı beraberinde toplum tarafından kadına ve erkeğe sosyal ve kültürel olarak uygun görülen davranışları ve kişilik özelliklerini zamanla ortaya çıkarmaktadır. Toplumsal cinsiyet rolleri olarak tanımlanan bu kavram, kadınları ve erkekleri belli alanlara hapsetmekte, bu toplumsal değerleri ve rolleri içselleştiremeyen bireylerin kendilerini toplumsal baskı altında hissetmelerine ve toplum tarafından dişlanabilmelerine neden olmaktadır. ${ }^{9,10}$ Örneğin; toplumun geleneksel yaşantısında kadınlara edilgen, pasif roller uygun görülürken; erkeklere etken ve aktif roller uygun görülmektedir. Ev işleri "doğal" olarak kadın işi, kamusal alanda politika ve çalışma "doğal" olarak erkek işi olduğu görüşü çoğu toplum tarafından benimsenip uygulanmasına neden olmaktadır. Kadınlara eğitimini tamamlayınca ya da tamamlamadan hemen evlen(diril)mesi, çok sayıda çocuk doğurmaları, bu çocukları yetiştirmeleri, aile yaşamında temizlik, ütü, yemek pişirme gibi rolleri üstlenmesi; erkeklere ise para kazanması, aile geçimini sağlaması daha uygun bir davranış olarak kabul görmektedir. 
Toplumsal cinsiyet rollerinin uzun vadeli etkileri göz önünde bulundurulduğunda bireylerin eğitiminden, aile hayatına, sosyal yaşamından meslek seçimine kadar etkili olmaktadır. ${ }^{11}$

\section{Toplumsal Cinsiyet Rollerine İlişkin Tutumları Etkileyen Faktörler}

Literatür incelendiğinde toplumsal cinsiyet rollerinin; tarihsel süreç içinde zaman, mekân, sınıf, ırk, yaş, aile tipi, ebeveynlerin öğrenim durumu, annenin çalışma durumu, kardeş sayısı, uzun süre yaşanılan yer, toplumun siyasi ve ekonomik koşulları gibi birden çok faktörden etkilendiği görülmektedir. ${ }^{11-16}$ Çelik ve arkadaşlarının (2013) 507 üniversite öğrencisi ile yaptıkları çalışmada; öğrencilerin cinsiyetinin, mezun oldukları lise türünün ve okumakta oldukları bölümlerin toplumsal cinsiyet rolleri üzerinde etkili olduğu belirlenmiştir. ${ }^{17}$ Başçı ve Giray'ın (2016) 3403 üniversite öğrencisinin toplumsal cinsiyet rollerine ilișkin tutumlarını değerlendirdikleri bir çalışmada; cinsiyet, medeni durum, aile tipi, sınıf, fakülte, annenin öğrenim durumu ve erkek kardeş sayısının toplumsal cinsiyet rolleri üzerinde etkili olduğu belirlenmiştir. ${ }^{18}$ Öngen ve Aytaç (2013) tarafından üniversite ögrencileri ile yapılan toplumsal cinsiyet rollerine yönelik algıları ve yaşam değerlerini araştırdıkları bir çalışmada; cinsiyetin, kültürün ve annenin çalışma durumunun etkili faktörler olduğu saptanmıştır. ${ }^{15}$ Aktaş ve arkadaşlarının (2018) hemşire ve ebelerin toplumsal cinsiyet rollerine yönelik tutumlarını ve etkileyen faktörleri ele aldıkları bir çalışmada; cinsiyet, yaş, medeni durum ve annelerin eğitim düzeyinin toplumsal cinsiyet rolleri üzerinde etkili olduğu belirlenmiştir. ${ }^{11}$ Zeybek ve Kurşun (2019) tıp fakültesindeki öğrencilerinin toplumsal cinsiyet rollerine yönelik tutumlarını değerlendirdikleri çalışmada; cinsiyet, doğum yeri, aile tipi, kardeş sayısı, ailenin ekonomik durumu, annenin ve babanın eğitim durumu, annenin çalışma durumu ve uzun süre yaşanılan bölgenin toplumsal cinsiyet rolleri üzerinde etkili olduğunu ifade etmişlerdir. ${ }^{19}$ Başar ve
Demirci (2018) Türkiye genelindeki üniversitelerde 1165 hemşirelik bölümü öğrencisinin toplumsal cinsiyet rollerine yönelik tutumlarını ve bu tutumlarını etkileyen nedenleri belirlemek amaciyla yaptıkları bir çalışmada; yaş, cinsiyet, yaşadıkları yerde geçirilen süre, kardeş sayıs1, aile tipi, ebeveynlerin eğitim durumu ve annenin çalışma durumunun toplumsal cinsiyet rollerine yönelik tutumları etkilediğini bildirmiștir. ${ }^{12}$ Kavuran ve Kaşıkçı (2018) 465 hemşirelik öğrencisinin cinsiyet eşitliğine yönelik bakış açılarını değerlendirdikleri bir çalışmada; cinsiyet, yaş ve eğitim yılının cinsiyet eşitliğine bakış açıs1 üzerinde etkili olduğunu belirlemişlerdir. ${ }^{13}$

\section{Ulusal ve Uluslararası Çerçevede Toplumsal Cinsiyet Kavramı}

Toplumsal cinsiyet eşitsizliğinin kadınların toplumsal konumlarını olumsuz yönde etkilediği ve bunun önüne geçilmesi gerektiği ilk olarak 1995 yılında Pekin'de düzenlenen “4. Dünya Kadın Konferansı'nda yer verilmiștir. $\mathrm{Bu}$ konferans kapsamında erkek ve kadın eşitliğinin sağlanabilmesi için toplumsal cinsiyete bakıș açısının tüm politika ve programlarda yer alması gerektiğinin önemi vurgulanmıştır. ${ }^{20}$

Ülkemizde son y1llarda toplumsal cinsiyet eşitliğini ortaya koymak için yapılan çalışmalarda; sosyal ve ekonomik yönden kadınların durumlarına yönelik veriler göz önünde bulundurulduğunda sürekli olumlu yönde bir iyileșmenin olduğu fakat hem ulusal hem de uluslararası düzeyde bu iyileşmenin istenilen düzeyde olmadığ1 görülmektedir. 2016 yılında Birleşmiş Milletler (BM) tarafindan yapılan Toplumsal Cinsiyet Eşitsizliği Endeksi'ne bakıldığ1 zaman Türkiye'nin, 159 ülke içinde 71 . sırada yer aldığı; diğer yandan 2017 yılındaki Dünya Ekonomi Forumu Küresel Toplumsal Cinsiyet Uçurumu Raporu'nda ise 144 ülke içinde 128. Sirada yer almıștır. Ayrıca Türkiye bu iki raporda da geçmiş yıllara göre tam anlamda bir ilerleme kaydedememiştir. "Karşılaștırmalarla 81 İl İçin Toplumsal Cinsiyet Eşitliği Karnesi-2018" raporunda eşitlikçi iller sıralamasında ilk sırada İstanbul 
yer alırken bunu sirasiyla Rize, Ankara, Bursa, Tunceli, Bolu, Antalya, Eskişehir, Düzce ve Kocaeli takip etmiştir. Eşitsizliğin en yüksek olarak belirlendiği illerin başında Ağrı gelirken bunu sırasıyla Afyon, Yozgat, Niğde, Muş, Iğdır, Bitlis, Kars, Siirt ve Ardahan takip etmiştir. $\mathrm{Bu}$ raporun sonucunda; ülkemizde kadınların, sosyal ve ekonomik durumlarında olumlu yönde bir iyileşme olduğu, fakat kadınların toplumdaki yaşamları incelendiğinde istenen ve kadınların hak ettiği noktaya ulaşamadıkları söylenebilir. ${ }^{21}$

İnsan Hakları Evrensel Beyannamesi'nde "Herkes 1rk, renk, cinsiyet, dil, din, siyasal ya da başka türden kanaat, ulusal ya da toplumsal köken, mülkiyet, doğuş veya başka türden statü gibi herhangi bir ayrım gözetilmeksizin, bu Beyannamede belirtilen bütün hak ve özgürlüklere sahiptir." denilmektedir (Kurulu, 1948). Bu hüküm şüphesiz olarak İnsan Hakları Evrensel Beyannamesi'nde, evrensellik özelliğini gösteren en önemli düzenlemelerden biri olarak karşımıza çıkmaktadır. Bu madde hiçbir şekilde insanlar arasında ayırımın yapılmaması gerektiğini, ifade edilen bütün hakların bütün insanlar için aynı oranda ve kısıtlamasız bir şekilde geçerli olduğunu göstermektedir. ${ }^{22}$ Fakat geçmişten günümüze kadar toplumsal yaşamın çoğu alanında kadınlar, erkeklerden daha düşük statüde yer almış ve insan haklarından daha az yararlanabilmişlerdir. Özellikle bu eşitsizlik eğitim durumu, evlilik ve aile içi yaşam/roller, sağlık hizmetlerinden yararlanma, çalışma yaşamı, siyaset ve karar mekanizmasına katılım gibi alanlarda kendini daha çok göstermiştir. ${ }^{4}$

Kadınlar için çok önemli bir uluslararası sözleşme olan Kadınlara Karşı Her Türlü Ayrımcılığın Önlenmesi Sözleşmesi (CEDAW)'nin amacı doğrultusunda; kişisel, kültürel, sosyal, ekonomik, siyasal veya diğer alanlardaki erkek ve kadın eşitliğine dayanan temel özgürlüklerin ve insan haklarının, medeni durumları her ne olursa olsun kadınlara da tanınmasını ve kadınlarında bu haklardan faydalanmalarını engellemeye veya hükümsüz kılmaya yönelik veya bu sonucu ortaya çıkaran cinsiyete dayalı herhangi bir kısıtlama, ayrım veya dışlama kadına karşı ayrımcılık olarak ifade edilmiştir. ${ }^{23} \mathrm{Bu}$ sözleşmede; "Toplumsal Cinsiyet Eşitliği’”nin sağlanması, her alanda ayrımcılığın önlenmesi ve önüne geçilmesi, kadınların hak ihlallerine uğramadan yaşamalarını kolaylaştıracak tedbirlerin alınması birçok maddeyle kapsamlı biçimde ele alınmıştır. ${ }^{24}$

2015 yılında New York'ta yapılan Türkiye'nin de içinde bulunduğu ve 193 ülke tarafından imzalanan $\mathrm{BM}$ Sürdürülebilir Kalkınma Zirvesi'nde, “2030 Sürdürülebilir Kalkınma Hedefleri" nin 5.hedefi "Toplumsal cinsiyet eşitliğini sağlamak ve tüm kadın ve kız çocuklarını güçlendirmek" amacını içermektedir. Bu hedef kapsamında her alanda kız çocuklarına ve kadınlara yönelik ayrımcılığın her türünün ortadan kaldırılması, kadınların ve kız çocuklarının güçlendirilmesi amaçlanmaktadır. ${ }^{25}$

Ayrıca ülkemizde son yıllarda Toplumsal Cinsiyet Eşitliği Ulusal Eylem Planı (20082013) ve Kadının Güçlenmesi Strateji Belgesi ve Eylem Planı (2018-2023) ile toplumsal cinsiyet eşitliğinin geliştirilmesi, kadınların sağlık, ekonomi, eğitim, karar alma mekanizmalarına katılım ve medyada güçlendirilmesi konusunda temel amaç, hedef, strateji ve faaliyetlere yer verilmiştir. 26,27

\section{Hemşirelik Mesleği ve Tarihi}

Hemşireler; bireyin, ailenin ve toplumun sağlı̆̆ını, esenliğini koruma ve geliştirme, hastalı halinde iyileştirme ve hastalıkları önlemede etkin rol oynayan sağlik profesyonelleridir. Tarih boyunca toplum içinde ve hastanelerde hasta insanların bakımı ile ilgilenen hemşirelik mesleğinin, çağdaş anlamda Kırım Savaşı'nda (1854 1856) Florence Nightingale (1820-1910) ile başladığ 1 bilinmektedir. ${ }^{28}$

Ülkemizde 1954 yılında çıkarılan Hemşirelik Kanunu, hemşireyi "kadın" olarak tanımlamış ve uzun yıllar erkeklerin hemşire olarak çalışmasına olanak sağlamamıştır. ${ }^{29} 50$ yıldan daha fazla yürürlükte kalan bu yasa, hemşireliğin "bir 
etmeye itmiștir. $^{33}$ Kaya ve arkadaşlarının

kadın mesleği” olduğuna dair maddeyi içinde bulundurduğu ve günümüzün gereksinimlerine yanıt vermediği için, Ocak 2007'de "Hemşirelik Kanununda Değişiklik Yapılmasina Dair Kanun" ile değiştirilmiştir. ${ }^{30} \quad$ 2007'de yapılan değişiklikle erkeklerin hemşirelikte yer alması ile hemşirelik mesleğindeki cinsiyet ayırımı ortadan kalkmaya başlamıştır. Ülkemizde 2006-2007 akademik yılında erkek hemşirelik lisans öğrenci sayısı 27 iken, 2018-2019'da lisans 20.343, yüksek lisans 490, doktora 74'e ulaşmıştır. ${ }^{31-32}$ Hemşireler hemşirelik hizmetlerini hümanistik, etik kurallara göre uygun, multidisipliner ve holistik (bütüncül) yaklaşımla yerine getirirken, toplumsal cinsiyet rolleri karşılaştıkları engellerden biridir. Çoğu hemşirenin kadın olması ve hemen hemen bütün dillerde ve kültürlerde "hemşire" anlam olarak kadına ait rol ve görevleri tanımlayan, ebe, k1z kardeş, sütanne vb. gibi kavramlar ile kullanılması, toplumsal roller ve statüler açısından hemşirelerin ister istemez kadın olması gerektiği algısını doğurmaktadır. İnsanlığın varoluşundan itibaren kadının anne şefkatinden kaynaklanan bebek, çocuk ve yaşlıların bakımı, beslenmesi ve iyileştirilmeleri geleneksel olarak kadın rolü olarak kabul görmüştür. Hemşirenin rollerinden biri olan bakım verme, gelenekselleştirilmiş kadın rolü ile özdeşleştirilmiştir. Bunlar meslek ile toplumsal cinsiyet kavramları arasındaki ilişkiyi göstermektedir. Oysa hemşirelik mesleği bir bütün olarak ele alındığında, cinsiyet ayrımcılığı olmaksızın/yapılmaksızın her iki cins tarafindan uygulanabilecek bir meslek olduğu bir gerçektir. ${ }^{12,33}$

Günümüzde hala "kadın" cinsiyetinin baskın olduğu bir meslek olarak kabul edilen hemşirelikte, erkeklerin mesleğe girmesi sürekli ve yavaş ilerlemektedir. Amerika'da erkek hemșirelerin oranı \%10, Jamika'da ise bu oran \%1'dir. Hemșirelik bakımının önem arz ettiği sağlık alanlarında, erkek hemşirelere karşı direnç devam etmektedir. Cinsiyete dayalı bu ayrımcilık, erkek hemşireleri genellikle acil ve yoğun bakım üniteleri gibi birimlerde çalışmayı tercih
(2011) toplumun erkek hemşire algısını belirlemek amacıyla yaptıkları çalışmada; katılımciların \%52,5'inin hemșirelik mesleğinde erkek hemşirelerin herhangi bir değişim yaratmayacağını; \%31,4'ünün ise hemşirelik mesleğinin toplumsal konumunun ilerletilmesinde erkek hemşirelerin katk1 sağlamayacağını ifade etmiştir. Katılımcıların \%15,4'ü erkek hemşirenin kendisine bakım vermesi sirasında şaşıracağını, \%15,9'u çekineceğini, \%16,6's1 ise utanacağını, belirtmiştir. Ayrıca erkek hemşirelerin çalışma alanları hakkında katılımcılar, erkek hemşirelerin \%39,7'sinin ameliyathane, yoğun bakım ve acil servis gibi alanlarda, \%45.6'sinın ise hastane ortamındaki tüm alanlarda çalışabileceğini ifade etmiştir. Hemşirelik mesleğini tercih eden erkekler, hemşirelikte kadın imajının ve özdeșleștirilmenin farkında olmakta ve daha öğrenciliğe adım atar atmaz kariyer yolundaki kararlarının uzun ve zor olacağını düşünmektedirler. ${ }^{34}$ Sis Çelik ve arkadaşlarının (2012) kadın doğum servislerinde yatan hastaların erkek hemşireler hakkında düşüncelerini belirlemek amacıyla yaptıkları çalışmada; hastaların \%53,2'si hemşirelik mesleğinin kadın mesleği olduğunu, \%52,5'i erkek hemşirenin kendisine bakım vermesinden rahatsız olacağını, \%57'si ise herhangi bir sorun yaşadığında (örneğin; sütüm gelmezse, kanamam olursa vb) bu durumu erkek hemşireye söylemekte sıkıntı yaşayacağını belirtmiştir. ${ }^{35}$ Hemşirelik mesleğini tercih eden öğrenciler arasında eğitim yıllarının başlarında erkek hemşirelere "hemşire" mi denilecek ayrımcılığı ile başlamaktadır. Ünsal ve arkadaşlarının (2010) farklı meslek gruplarındaki bireylerin erkek hemşirelere ilişkin görüşlerini ele aldıkları çalışmalarında; katılımcıların erkek hemşirelere ne şekilde hitap edecekleri ile ilgili net olamadıklarını ve katılımcıların hemşirmen, hemşir, hemşbay vb. gibi dokuz farklı hitap şekilleriyle erkek hemşireleri çağırdıklarını tespit etmişlerdir. Katılımcıların büyük çoğunluğunun erkek hemşirelere hemşire diye hitap edilmesi gerektiğini belirtmişlerdir. ${ }^{36}$ Rajacich ve 
arkadaşlarının (2013) 16 erkek hemşireyle yaptıkları odak grup görüşmesinde; cinsiyet temelli kalıpların iş memnuniyetsizliğine yol açtığını ve erkek hemşirelerin çoğunun kendilerine sadece hemşire diye hitap edilmesini istediklerini ifade etmişlerdir. Erkek hemşire ya da başka kelimelerin cinsiyet ayrımcılığına yol açtığı olduğu gerekçesi ile istemediklerini, doktorlara "erkek doktor" ya da "kadın doktor" şeklinde hitap edilmediği gibi kendilerine sadece hemşire denilmesi gerektiğini düşündüklerini ifade etmişlerdir. ${ }^{37}$ Kahraman ve arkadaşlarının (2015), 17 erkek hemşirelik öğrencisi ile yaptıkları derinlemesine mülakat görüşmesinde, erkek hemşire adaylarının özellikle arkadaş çevrelerinden alaylara ve yoğun bir eleştiriye maruz kaldıklarını ifade etmişlerdir. Ayrıca görüşmeler sonucunda; hemşirelik bölümünde okuyan erkek öğrencilerin genellikle alt ve orta ekonomik sinifa ait oldukları ve ekonomik kaygı nedeniyle bu mesleği tercih ettikleri belirlenmiștir. ${ }^{38}$ Chan ve arkadaşlarının (2014) 18 erkek hemşirelik öğrencisi ile yaptıkları yarı yapılandırılmış görüşmelerinde, erkek hemşirelik öğrencilerinin hemşirelik mesleğini tercih etme nedenlerinin "iyi ve istikrarlı bir gelir", "tatmin edici beklentiler" ve "profesyonel bir ünvan" olduğu belirlenmiştir. Ayrıca katılımcıların, erkek hemşirelerin obstetri ve pediatri kliniklerinde çalışmalarının doğru olmadığını destekledikleri daha çok bu alanlarda kadın hemşirelerinin yer almalarının doğru olacağını ifade ettikleri belirlenmiștir. ${ }^{39}$ Feito ve arkadaşlarının (2019) 159 öğrenci ve 386 hemșire ile yaptıkları tanımlayıcı bir çalışmada; hemşirelikte mesleki değerler algisında önemli cinsiyet farklılıklarının olduğu ve ayrımcılığın öğrenciler arasında daha belirgin olduğu belirlenmiştir. ${ }^{40}$ Liminana-Gras ve arkadaşlarının (2013) 98 erkek, 98 kadın hemşire ile yaptıkları çalışmada; kadın ve erkek hemșireler tarafından fiziksel güç gerektiren işlerin erkek hemşirelerin görevi olarak algılandığını, bu tip algıların da cinsiyet ayrımcılığını arttırdı ̆̆ını ifade etmişlerdir. ${ }^{41}$

\section{SONUÇ VE ÖNERILLER}

Sonuç olarak; sağlık alanında önemli bir yeri olan hemşirelik mesleğinin önündeki en büyük engellerden birinin, kadın ve erkeklerin meslekteki toplumsal cinsiyet rolleriyle ilgili olduğu görülmektedir. $\mathrm{Bu}$ eşitsizliğin erkeklerin uzun yıllardır meslekte yer almalarına rağmen devam eden bir sorun olduğu göze çarpmaktadır. Mesleğin gelişimi ve meslekte yaşanan cinsiyet ayrımcılığının ortadan kaldırılabilmesi için, toplumun bilinçlendirilmesi, hemşirelik mesleğinin daha iyi tanınması ve lisans eğitimi almış profesyonel hemşirelerin meslekte yer alması büyük önem taşımaktadır. Ayrıca üniversitelerde hemşirelik eğitimi veren akademisyenlerin, eğitimin ilk yıllarından itibaren meslekte yaşan cinsiyet ayrımcılığının her alanda mesleğin gelişiminde büyük bir engel olduğu konusunda öğrencileri bilinçlendirmeleri gerekmektedir. Klinikte çalışan hemşirelerin ve yöneticilerin ise bu konuda ciddi eğitimlerden geçirilmesi ve farkındalıklarının arttırılması hemşirelik mesleğinin hak ettiği yere gelmesi ve güçlenip örgütlenmesi açısından önemlidir.

\section{KAYNAKLAR}

1. Bingöl, O. (2014). "Toplumsal cinsiyet olgusu ve Türkiye'de kadınlı". Karamanoğlu Mehmetbey Üniversitesi Sosyal ve Ekonomik Araștırmalar Dergisi, 3, 108-14

2. Topuz, S. K., \& Erkanli, H. (2016). "Toplumsal Cinsiyet Bağlamında Kadın ve Erkeğe Atfedilen Anlamların Metafor Yöntemiyle Analizi”. Alternatif Politika. 8(2): 300-21.

3. Short, S. E., Yang, Y. C., \& Jenkins, T. M. (2013). "Sex, gender, genetics, and health. American journal of public health". 103 (S1), S93-S101.
4. Coşkun, A., \& Özdilek, R. (2012). "Toplumsal cinsiyet eşitsizliği: sağlığa yansıması ve kadın sağlığı hemşiresinin rolü”. Koç Üniversitesi Hemşirelikte Eğitim ve Araştırma Dergisi (HEAD). 9(3), 30-39.

5. Erbaydar, N. P. (2018). "Sosyallestirilmis Sağlık Hizmetlerinde Ebelerin Sağlık Ocağı İle İlişsisinin Mekânsal İncelemesi”. Fe Dergi.10 (2), 140-9.

6. Başar, F. (2017). "Toplumsal cinsiyet eşitsizliği: Kadın sağlığına etkisi”. ACU Sağlık Bil Derg. 3, 131-7. 
7. Vlassoff, C. (2007). "Gender differences in determinants and consequences of health and illness". Journal of health, population, and nutrition. 25 (1), 47-61.

8. Marcus, R., Harper, C., Brodbeck, S., \& Page, E. (2015) "Social norms, gender norms and adolescent girls: A brief guide". From the Knowledge to Action Resources Series. September 1-17.

9. Karasu, F., Göllüce, A., Güvenç, E., \& Çelik, S. (2017) "Üniversite Öğrencilerinin Toplumsal Cinsiyet Rollerine İlișkin Tutumları The Attitudes of the University Students' Regarding the Gender Roles". SDÜ Sağlık Bilimleri Dergisi. 8 (1), 21-27.

10. Uzun, Z., Erdem, S., Güç, K., Şafak-Uzun, A., \& Erdem, E. (2017). "Toplumsal cinsiyet algısı ve toplumsal cinsiyet rollerine eğitimin etkisi: Deneysel bir calıșma". Journal of Human Sciences. 14 (1), 678-93

11. Aktaş, S., Erkek, Z. Y., \& Korkmaz, H. (2018). “An examination of the attitudes of midwives and nurses towards gender roles and the influencing factors Ebe ve hemşirelerin toplumsal cinsiyet rollerine ilişkin tutumları ve etkileyen faktörlerin incelenmesi”. Journal of Human Sciences. 15 (2), 823-34.

12. Bașar, F., \& Demirci, N. (2018). "Attitudes of nursing students toward gender roles: a cross-sectional study". Contemporary Nurse. 54 (3), 333-344.

13. Kavuran, E. (2018). "Determination of Nursing Students" Perspectives at Ataturk University Health Sciences Faculty on Gender Equality”. International Journal of Caring Sciences. 11 (1), 108-17.

14. OECD. "Gender equality in education, employment and entrepreneurship: Final report to the MCM 2012". Paper presented at the Meeting of The OECD Council at Ministerial Level Paris. 2012.

15. Öngen, B., \& Aytaç, S. (2013). "Üniversite öğrencilerinin toplumsal cinsiyet rollerine ilişkin tutumlari ve yaşam değerleri ilişkisi”. Sosyoloji Konferansları. 48, 1-18.

16. Uçar, T., Derya, Y. A., Karaaslan, T., \& Tunç, Ö. A. (2017) "Üniversite öğrencilerinin toplumsal cinsiyet rollerine ilişkin tutumları ve şiddet davranışları”. Sürekli Tıp Eğitimi Dergisi. 26 (3), 96-103

17. Çelik, A. S., Pasinlioğlu, T., Gonca, T., \& Koyuncu, H. (2013). "Üniversite öğrencilerinin cinsiyet eşitliği tutumlarının belirlenmesi”. Florence Nightingale Hemşirelik Dergisi. 21 (3), $181-6$.

18. Başçı, B., \& Giray, S. (2016). "Üniversite öğrencilerinin toplumsal cinsiyet rollerine ilişkin tutumlarinin çok değişkenli istatistiksel tekniklerle analizi”. Journal of Life Economics. 3 (4), 117-42.

19. Zeybek, V., \& Kurşun, M. (2019). “Tıp fakültesi öğrencilerinin toplumsal cinsiyet rollerine ilișkin tutumları”. Pamukkale Tıp Dergisi. 12 (2), 225-33. DOI: 10.31362/patd.468353.

20. https://www.tbmm.gov.tr/komisyon/kefe/docs/pekin.pdf KSSGM, Pekin+5 Siyasi Deklarasyonu ve Sonuç Belgesi (Türkçe-İngilizce) Pekin Deklarasyonu ve Eylem Platformu, Ankara, Eylül, 2001. Erișim tarihi: 13.05.2020.

21. Kavas, A. (2018). "Karşılaştırmalarla 81 İl İçin Toplumsal Cinsiyet Eşitliği Karnesi”. Ankara: TEPAV.

22. Hekimler, A. (2009). "İnsan Hakları Evrensel Beyannamesi'nin Kabul Edilişinin 60. Yıl Dönümünde Taşıdığı Anlam ve Önemi”. Namık Kemal Üniversitesi Sosyal Bilimler Enstitüsü Sosyal Bilimler Metinleri (2)

23. https://www.tbmm.gov.tr/komisyon/kefe/belge/uluslararasi_bel geler/ayrimcilik/CEDAW/CEDAW_Sozlesmesi_ve_Ihtiyari_Pr otokolu.pdf. Erişim tarihi: 14.05.2020.
24. https://www.kadinininsanhaklari.org/wp-content/uploads/ 2018/08/KIHYC_ILO_Oturum_4_Kitapcik_18.03.16.pdf. Erişim tarihi: 14.05.2020.

25. https://sustainabledevelopment.un.org/content/documents/ $21252030 \% 20$ Agenda $\% 20$ for\%20Sustainable\%20Development \%20web.pdf Erişim tarihi: 13.05.2020.

26. Müdürlüğü, K. S. G. Toplumsal Cinsiyet Eşitliği Ulusal Eylem Plan1. 2008.

27. Kadının Güçlenmesi Strateji Belgesi ve Eylem Planı (20182023).

http://www.sp.gov.tr/upload/xSPTemelBelge/files/RySPo+Kadı nin Guclenmes1_Stratej1_Belges1_Ve_Eylem_Planı_2018 2023_.pdf

28. Topuksak, B., \& Kublay, G. (2014). "Florence Nightingale'den Günümüze Hemşirelik Eğitiminde Neler Değişti?” Avrupa ve Türkiye'de Modern Hemşirelik Eğitimi.

29. http://www.istanbulsaglik.gov.tr/w/mev/mev_kan/hemsirelik_k anunu.pdf. Erişim tarihi: 13.05.2020.

30. https://www.resmigazete.gov.tr/eskiler/2007/05/200705023.htm.Erișim tarihi: 12.05.2020

31. Gönç, T. (2016). "Hemşireliğin geleceği mesleğin cinsiyetsizleşmesini vadediyor mu? Erkek ve kadın hemșirelik öğrencilerinin meslek ve toplumsal cinsiyeti ilişkilendirme eğilimlerinin sosyolojik analizi”. Fe Dergi: Feminist Eleştiri. 8 (1)

32. https://istatistik.yok.gov.tr/, file://C:/Users/fatma/Downloads/2019 T106.pdf Erișim tarihi: 12.05.2019.

33. Celebi, E., \& Kargin, M. (2019). "Social gender and nursing in Turkey: A qualitative research. JPMA". The Journal of the Pakistan Medical Association. 69 (8), 1184-6.

34. Kaya, N., Turan, N., \& Öztürk, A. (2011). "Türkiye'de erkek hemșire imgesi”. Uluslararası İnsan Bilimleri Dergisi. 8(1): 1630 .

35. Çelik, A. S., Pasinlioğlu, T., Çilek, M., \& Çelebi, A. (2012) "Kadın doğum servislerinde yatan hastaların erkek hemşireler hakkındaki düşüncelerinin belirlenmesi.” Anadolu Hemşirelik ve Sağlık Bilimleri Dergisi, 15 (4), 254-261.

36. Ünsal, A., Akalın, İ., \& Yilmaz, V. (2010). "Farklı meslek çalışanlarının erkek hemşirelere ilişkin görüşleri’. Uluslararası İnsan Bilimleri Dergisi. 7 (1), 420-31

37. Rajacich, D., Kane, D., Williston, C., \& Cameron, S. (2013).' If they do call you a nurse, it is always a "male nurse": Experiences of men in the nursing profession". Paper presented at the Nursing forum

38. Kahraman, A. B., Tunçdemir, N. O., \& Özcan, A. (2015) "Toplumsal cinsiyet bağlamında hemșirelik bölümünde öğrenim gören erkek öğrencilerin mesleğe yönelik algıları”. Sosyoloji Araștırmaları Dergisi. 18 (2), 108-144

39. Chan, Z. C., Chan, Y.-T., Yu, H.-Z., Law, Y.-F., Woo, W.-M., \& Lam, C.-T. (2014). "An ethnographical study on the academic experiences of Chinese male nursing students". Nurse education in practice. 14 (2), 130-6.

40. Fernández-Feito, A., Basurto-Hoyuelos, S., Palmeiro-Longo, M., \& García-Díaz, V. (2019). "Differences in professional values between nurses and nursing students: a gender perspective". International nursing review. 66, 577-89.

41. Liminana-Gras, R. M., Sanchez-Lopez, M. P., Román, A. I. S. S., \& Corbalan-Berna, F. J. (2013). "Health and gender in female-dominated occupations: the case of male nurses". The Journal of Men's Studies. 21 (2), 135-48. 